\title{
Contemporary Political Theory Annual Prize of $£ 500$ for an article published in Volume 11, 2012
}

\author{
Contemporary Political Theory (2013) 12, 254. doi:10.1057/cpt.2013.34
}

We are delighted to announce that the Contemporary Political Theory Annual Prize for 2012 has been awarded to:

Diana Coole, Professor of Political and Social Theory at Birkbeck, University of London, UK, for her article 'Reconstructing the elderly: A critical analysis of pensions and population policies in an era of demographic ageing', Contemporary Political Theory, Volume 11, Number 1 (February 2012), pp. 41-67.

The judges' citation was as follows:

This article is an elegantly crafted and innovative analysis of the changing place of the elderly in contemporary social and political life. It undertakes a comprehensive survey of discourses concerning an important sector of the world's population and the site of considerable policy activity, a hitherto neglected field of research for political theory and politics. This timely and accessible analysis demonstrated an impressive breadth of reflection and conceptual sophistication without losing sight of the need to direct theory at a 'real world' issue of universal concern. It was an exemplary piece of political theory that should stimulate interest well beyond the discipline.

The judging panel was chaired by Professor James Martin, Goldsmiths, University of London, UK, and supported by Professor Michaele Ferguson, University of Colorado, USA, and Professor Yves Winter, McGill University, Toronto, Canada. 